\title{
2. The Art of Reality
}

\begin{abstract}
This chapter is a contemporary examination of cinema as the art of reality: I explain the ways in which Bazin understands the complex, often paradoxical relation between reality and its image, which places him in direct dialogue with existing classical film theories as well as foundational scientific and philosophical concepts. Consequently, I extend his line of thought to include more recent examples involving digital image technologies that illustrate the relevance of integral realism today. I conclude the chapter with an exploration of existentialist influences in Bazin's notion of integral realism.
\end{abstract}

Keywords: realism, editing, scientific metaphors, existentialism

Reality is not art, but a realist art is one which can create an integral aesthetic of reality.

André Bazin, 1948d

It's the paradox of film that an abstract idea can only be expressed by means of the most concrete form of representation, namely reality. This is its strength, but also its risk.

André Bazin, 1953e

Regardless of Bazin's fierce rejection of prescriptive aesthetics, several of his major essays could easily be - and often have been - qualified as an attempt at formulating fundamental laws or basic principles of cinema: a theory of film. In 'The Myth of Total Cinema' (1946), for instance, he approaches film

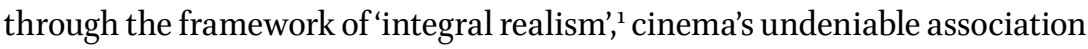

1 In his 2009 translation, Timothy Barnard translates réalisme intégral as 'complete realism'; this, however, does not do justice to the term originally chosen by Bazin, as it empties it of its mathematical reference, which I explain in the following chapter (see, 2.2 Integral Realism: Reality and Cinema 'Ultimately Equal').

Joret, B., Studying Film with André Bazin, Amsterdam: Amsterdam University Press, 2019 DOI: 10.5117/9789462989528/CHO2 
with reality, which he grounds in the ontology of film, explained in another seminal essay, 'The Ontology of the Photographic Image' (1945). Perhaps uncomfortable with the philosophical weight of the term, he reformulates 'ontology' in lay terminology for his introduction to What Is Cinema? (1958): 'in less philosophical terms: cinema as the art of reality.' Realism, Bazin's cornerstone concept, supposedly led to aesthetic prescriptions, such as his assumed prohibition of editing or his preference for long takes and depth of field. While these texts are now considered foundational for the discipline, it is nevertheless because of his focus on realism that Bazin's work is often considered outdated, unable to account for the many technological changes cinema has encountered since the digital turn, which radically overthrew the ontology of film. And yet, Bazin's film analyses build on philosophical questions and scientific references and metaphors that upon closer examination reveal a useful interpretative framework - solid yet flexible enough to stand the test of time.

This chapter is a contemporary examination of cinema as the art of reality: I explain the ways in which Bazin understands the complex, often paradoxical relation between reality and its image, which places him in direct dialogue with existing classical film theories as well as foundational scientific and philosophical concepts. Consequently, I extend his line of thought to include more recent examples involving digital image technologies that illustrate the relevance of integral realism today. I conclude the chapter with an exploration of existentialist influences in Bazin's notion of integral realism.

\subsection{Paradox: The Existence of Film}

By way of introduction, I propose to take a closer look at one particularly outstanding critique relating to documentary authenticity, namely Bazin's discussion of Thor Heyerdahl's documentary film Kon-Tiki (1950). Heyerdahl's renowned exploratory expedition was set out as a counter-proof to established theories of migration: according to him, the people of Polynesia had travelled westwards on a raft from the coast of Peru around 500 BC. The hypothesis was rejected by Heyerdahl's professors, and no serious publisher was interested in disseminating his research. As ultimate proof of this theory, Heyerdahl accompanied his thesis with a real-life expedition, documented by film. He built a raft, in original style and with the materials 
the Peruvian Indians would have used, and embarked on the expedition with five fellow explorer-scientists. Their documentary film, in Bazin's words, 'does not exist':

Kon-Tiki is the most beautiful of all films, but it does not exist! [Kon-Tiki est le plus beau des films mais il n'existe pas!'] Like those moss-covered stones that, surviving, allow us to reconstruct buildings and statues that no longer exist, the pictures that are here presented are the remains of an unfinished creation about which one hardly dares to dream. ${ }^{3}$

Because of the crew's inexperience in filmmaking and the spatial restriction of the raft, the film lacked intriguing shots, and the material itself was of extremely poor quality. But rather than weakening the film, Kon-Tiki's uninviting shooting conditions enhanced the documentary authenticity so dear to Bazin:

These few images in the midst of a flood of film rolls with close to no objective interest, are like invaluable and very moving flotsam on the monotonous swell of the ocean. It's that their poor state is not experienced as a lack; the huge gaps in these films are in reality a fullness, the fullness of human adventure to which [these images] so fully testify only through their emptiness. ${ }^{4}$

In fact, Bazin's preference for an authentic image over aesthetic perfection extends beyond the particular case of Kon-Tiki into his wide-ranging understanding of cinematic realism, more precisely, in what he termed 'ontogenetic realism': in short, for an image to be authentic, it usually means it doesn't look perfect.

Whereas he would name this procedure only in 1958, the idea of an ontogenetic realism 5 is already clearly formulated in 'The Ontology of the

3 Bazin, 1953-1954, EC p. 2562; Transl. Gray, 2005, p. 160.

4 Bazin, 1955a, EC p. 1703.

5 For more on Bazin's usage of the term 'ontogeny', I refer to Hervé Joubert-Laurencin's analysis in Le Sommeil paradoxal: 'This term appears in an addition from 1958 [...], which suggest, given its rarity, that it was included out of a desire for belated accuracy, able to qualify as scientistic; it indeed appears more serious, and is practically never used in any of its two meanings in French' (2014, p. 20). Stepping away from the common explication of Bazin's ontogeny thesis in biological and philosophical terms, in particular Dominique Chateau's in Cinéma et philosophie (2003), Joubert-Laurencin writes: 'the phrase in Bazin means that the functioning of cameras for both photography and cinema (the "genesis" extends from the mechanical operation of image creation) is known just well enough by the average viewer to credit in his eyes the resulting 
Photographic Image': 'The image may be out of focus, distorted, devoid of colour and without documentary value; nevertheless, it has been created out of the ontology of the model. ${ }^{6}$ Similarly, in defence of Kon-Tiki's poor cinematography, Bazin ultimately argues for decay and dissemblance as a sign and proof of authenticity:

[...] this film is not made up only of what we see - its faults are equally witness to its authenticity. The missing documents are the negative imprints of the expedition - its inscription chiselled deep. ${ }^{7}$

It is precisely because we do not see the image clearly that we can rely on its authenticity: if I were to film a murder in the streets with my cell phone, the shakiness and blurred quality of the footage would in fact be much more convincing than the same scene captured in a smooth 360 degree shot. This negative imprint of adventure, which implies authenticity without direct visibility, is put at work most clearly in Bazin's description of a shark attack scene: 'it is not so much the photograph of the shark that interests us as the photograph of danger.'8 Ever since, simply filming a shark attack, regardless of the aggravating circumstances of Heyerdahl and his crew, has proven to be anything but easy. Even Steven Spielberg, hoping to achieve a higher degree of realism, decided to shoot Jaws (1975) on location rather than in the usual massive bassins of Hollywood studios, it was his mechanical shark which disappointed him most, since it failed drastically in conveying the imminent danger of a real shark attack; in such cases, Spielberg nicknamed the shark 'the great white turd'. ${ }^{9}$ Moreover, in the context of this discussion it is intriguing to note that the shooting conditions on location particularly aggravated and accentuated the shark's artefactual qualities: it sank immediately when put to water at Martha's Vineyard, and the salty ocean water repeatedly damaged the material of the mechanical shark. For these reasons, Spielberg ended up filming with subjective point of view shots assuming the position of the shark so that most scenes were recorded without explicitly showing it. This dramatic technique, then, brings us back full circle to Bazin's argument concerning

image as a faithful trace of recorded reality, regardless of its "objective" qualities of resemblance' (Joubert-Laurencin, 2014, p. 21).

6 Bazin, 1945, EC p. 2557; Transl. Barnard, 2009, p. 8.

7 Bazin, 1953-1954, EC p. 2562; Transl. Gray, 2005, p. 162.

8 Ibid.; Transl. Gray, p. 161. [Slightly modified: Gray turns Bazin's requin into a whale and adds an emphasis on 'danger' that is absent in the original text.]

9 'Jaws: Trivia.' The Internet Movie Database. IMDB.com. Web. 28/05/2014<http://www.imdb. com/title/ttoo73195/trivia?ref_=tt_trv_trv> 
the shark attack in Kon-Tiki. The paradox of documentary authenticity crystallizes in the burden of shark attacks in the cinema. In a similar way, in a review of The Silent World (Jacques-Yves Cousteau \& Louis Malle, 1956), Bazin derives a fundamental principle of authenticity from the indispensable bond between the cinematographic image and reality:

What the film records is the repetition of events that should or could have, in all likelihood, happened the same way in the absence of any camera. This principle of course precludes fantasies like 'death struggle with a shark'. Not because ultimately the event is inconceivable but because its repetition would be the denial of the danger that imbues the event with pathos. Either the shark is harmless and it is an ignoble comedy, or it is dangerous and the cameraman who continues to film is found guilty of failing to assist a person in danger. ${ }^{10}$

So Bazin's argument of cinema as an art of reality manifests itself in the analysis of sharks throughout the history of cinema, and it formulates the fundamental question pertaining to documentary authenticity, namely: did the camera influence the event? Concerning sharks in cinema, the question then is not one of probability but of authenticity.

Of course, this discussion on documentary authenticity presumes analogue film, the 'photographic image' on which Bazin's ontological realism is built. Yet, from the perspective of myth, the same logic may apply just as well to contemporary, digital filmmaking: if bad quality testifies to a film's authenticity, crisp aesthetics might attest to its inauthenticity. Interestingly, a recent feature film remake of Kon-Tiki by Joachim Rønning and Espen Sandberg (2012) includes a similar shark attack scene, in which precisely those limitations that, for Bazin, proved the documentary authenticity of the original have been spectacularly disregarded. The film makes abundant use of helicopter shots and underwater filming, and the shark attack scene in particular is a remarkable display of over five hundred instances of computer-generated imagery and effect shots. The contemporary Kon-Tiki expedition therefore stands in stark opposition to the description by Bazin of the original Kon-Tiki documentary:

Naturally enough, there could be no traveling shots, no dolly shots, and scarcely a chance to get a full shot of the 'vessel' from the little boat bouncing on the waves astern. Finally, and most important of all, whenever 
something of significance occurred, the onset of a storm for example, the crew were too busy to bother about running a camera. The result was that our amateur filmmakers simply wasted endless reels filming their pet parrot and the rations provided by the American armed force. But when an explicit moment arrives, say a whale hurling itself at the raft, the footage is so short that you have to process it ten times over in the optical printer before you can even spot what is happening. ${ }^{11}$

In the context of Bazin's $195^{2}$ critique, and more generally in light of his views on ontogenetic realism, the remake of the Kon-Tiki expedition, and the shark attack scene in particular, can now be seen as a surprising take on the status of the image in today's contemporary visual culture. Rønning and Sandberg's film enters into a direct dialogue with cinematic realism, of which the re-enactment of the shark attack scene is indeed an intriguing case, given the implications of Bazin's critique outlined above. In an interview with The Hollywood Reporter, commenting on the difficulty involved in shooting Kon-Tiki, Sandberg and Rønning state:

Rønning: To make a whale shark and other sharks, CGI needed to be at a certain level. Personally, we had never seen sharks in movies that we felt were one hundred percent life-like.

Sandberg: The reason it worked so well in Jaws is because you basically never see the shark. We had to have it on deck and everything. So, I think that was part of the reason it hadn't been made before because it would have been too expensive. ${ }^{12}$

Under no circumstance would Heyerdahl and his crew have been able, or indeed willing, to shoot the shark attack scene from below the water surface, for instance. And for that matter, neither did Spielberg or anyone else. Thus, while Kon-Tiki from 2012 in many aspects radically overturns Bazin's notion of ontogenetic realism, it is most definitely an impressive exposé of the possibilities of CGI that produce the very visibility that Bazin considered inconceivable, provided that the shark is inoffensive or, in this case, virtual: at most a dummy. ${ }^{13}$

11 Bazin, 1953-1954, EC p. 2562.

12 Trier and Weinstein. "Kon-Tiki” Directors Discuss the Making of Their Offshore Epic (Q\&A).' The Hollywood Reporter. Web. 28/05/2014 <http://www.hollywoodreporter.com/news/ kon-tiki-directors-discuss-making-447386>.

13 For a short clip on the shooting conditions 'in open water' of the 2012 remake, see: 'Kon-Tiki: The Incredible True Story: Shooting in Open Water.' National Geographic. [Accessed 28/05/2014] 
Although there are many examples from which to draw illustrating subjects that pose a serious threat to documentary authenticity, the filmic image of the shark stands out in this regard, and it is this subject that Bazin uses to explain documentary authenticity. Those who have seen Monster Shark (Lamberto Brava, 1989), Cruel Jaws (Bruno Mattei, 1995) or Deep Blood (Raffaele Donato \& Joe D'Amato, 1990) are aware that shark films often build on explicit B-movie aesthetics whenever a shark is clearly visible. Throughout film history, sharks in cinema have been 'jumping the shark', so to speak, and the act of filming an attack (even disregarding the difficult circumstances for Heyerdahl and his crew) has proven to be a cumbersome endeavour. ${ }^{14}$ Where Spielberg liberally employed the artifice of a rubbery looking mechanical shark in his attempt to depict danger, CGI effects were put to use excessively during the shark attack scene in Kon-Tiki's recent remake from 2012. In the case of Kon-Tiki 2012, CGI radically overturns the logic of Bazin's ontogeny thesis: the visibility of the shark becomes proof of the inauthenticity of the image - proof, at least, that the shark was never filmed (and that the cameraman therefore did not fail in his duty to rescue). Evidently, the image of the shark in Kon-Tiki 2012 is nothing like the photograph of danger of which Bazin spoke. And yet, to this day the very heart of the problem - a shark on film - remains the same. CGI thus appears to have brought the contemporary cinematographic image to the reverse side of the ontogeny argument, where the result predominates over the authenticity derived from the photographic genesis of the image: the dummy comes as the culmination of a history of mechanical sharks in cinema.

\subsubsection{Editing Prohibited? CGI and the Dummy of Danger}

The abundant use of CGI in the Kon-Tiki remake inevitably brings us to the question of editing: in his famed essay 'Editing Prohibited' from 19531957 , Bazin generally rules out montage or editing when it would mean

$<$ http://channel.nationalgeographic.com/channel/videos/shooting-in-open-water/>. For an extensive CGI breakdown reel, see: 'Kon-Tiki: Complete VFX-Breakdown.' YouTube. [Accessed 28/05/2014] <http://www.youtube.com/watch?v=gFpL2XzAn44>.

14 One example in particular illustrates the danger involved when filming attacks 'too realistically': Shark! (1969) by Samuel Fuller is dedicated to 'fearless stuntmen who repeatedly risked their lives against attacks in shark-infested waters during the filming of this picture...' (IMDb, 'Shark! Trivia'). One stuntman, Jose Marco, was in fact killed on camera while fighting a supposedly sedated white shark: Fuller quit the production when the company used the incident to promote the film. 
the annihilation of danger. Together with ontological realism, this topic is generally considered Bazin's most prescriptive and therefore medium essentialist film theory. From this perspective, his views on documentary authenticity and cinematic specificity directly relate to his condemnation of editing. However, rather than entirely dismissing editing as anti-cinematic, Bazin is in fact much subtler when he writes that 'there are cases where, far from constituting the essence of cinema, editing is its negation'. ${ }^{15}$ It appears that Bazin's title is in fact a rhetorical play on persisting theories of editing, which were in Bazin's days among the most essentialist. In this manner, 'Editing Prohibited' is not a categorical dismissal of the cinematic possibilities montage; rather, his ban on editing is an ironic attempt to trespass the borders of prescriptive film theories.

In his deepening of what appears to be Bazin's one and only aesthetic commandment, French film critic Serge Daney (1944-1992) indeed describes editing as a correlation of risk. In an essay from 1972 entitled 'The Screen of Fantasy (Bazin and Animals)', he writes:

We can see that what justifies the prohibition of editing is [...] the nature of what is being filmed, the status of the protagonists (in this case men and animals) who are forced to share the screen, sometimes at the risk of their lives. The ban on editing is a function of this risk. ${ }^{16}$

Daney further develops the paradox of irreversibility on screen in qualitative terms, as it risks being effaced by quantitative repetition. The same principle, we have seen, guides the authenticity argument of an invisible shark on screen, thereby running the risk that the film itself ceases to exist: 'Kon-Tiki is the most beautiful of all films, but it does not exist! [...] [these images are] the remains of an unfinished creation about which one hardly dares to dream.17 And just as the photograph of the shark could be the negation of danger, so too can editing (not always, but in specific cases) be the negation of cinema. But if the question of documentary authenticity involves minimizing the camera's influence on the event, the inevitable consequence of this would be the effacement of cinema itself. Conversely, Bazin proposes Man of Aran (Robert J. Flaherty, 1934) as an example, a fictional documentary of everyday struggles on the western coast of the Aran Islands, where at one point we clearly see a shark for an extended period of time, soothing right beneath 
the water surface. In this case, 'splendid cinematography' rids the shark of its essential features. In the context of sharks, Bazin then introduces what he terms an 'insoluble dilemma" ${ }^{18}$ between reality and its abstraction on screen: what can the camera capture from the event without destroying its essence? But also: if cinema cannot be more than an extraction from reality, then why bother making films at all?

Where Heyerdahl used a real-life expedition to prove his theory, Bazin saw the film's poor aesthetic quality as proof of its authenticity: both men obviously value objectivity and proof, in science and on film. Using the exact same materials for the raft as the Peruvian natives would have in their time, the 1947 expedition happened under the exact same conditions of $500 \mathrm{BC}$ (reminiscent of the scientific principle of replicability). Similarly, the camera they brought along did not influence the events on board (nothing, not even the shark attack, was staged). Just as Heyerdahl's motivation was a scientific one, the following section shows that Bazin, too, implicitly engages with scientific principles, such as observation and probability theory, which shape his understanding of authenticity and ultimately formulate his critique of existing film theories.

\subsubsection{Authenticity: Bazin's Shark and Schrödinger's Cat}

The implications of Bazin's analysis of sharks perfectly illustrate the way in which realism on screen always necessitates that 'some aspect of reality will always have to be sacrificed to reality'. ${ }^{19}$ In both Heyerdahl's lived documentary as well as Spielberg's feature film, the very properties of the image are sacrificed to enhance the authenticity of the attack. In this manner, the screen becomes a double-edged sword, as each gain in reality involves a loss in the image, and vice versa.

From this perspective, the analysis of the shark in Kon-Tiki appears to lean towards a similar observational theory as initiated by Erwin Schrödinger (1887-1961), who set out to challenge the Copenhagen interpretation of quantum indeterminacy, in particular their concept of the wave- or psifunction which calculates the probability of objective reality. ${ }^{20}$ After Werner Heisenberg's description in 1927 of the so-called uncertainty principle,

18 Ibid., EC ibid.

19 Bazin, 1948c, EC p. 355; Transl. Barnard, 2009, p. 232.

20 Quantum indeterminacy, also called the uncertainty principle, is the fundamental assertion in quantum physics that the state of a certain physical system cannot fully determine the actual observed values. Diverging from classical mechanics, the study of phenomena on a quantum level cannot predict or determine the behavior of individual particles. Beyond being an apology 
natural science acknowledged a radical shift in perspective, as it turned its back to physical determinism. Where classical mechanics is based on the assumption of scientific reproducibility, which assumes that if all conditions are meticulously recreated, repeated scientific experiments should produce the same results, quantum physics, on the contrary, is founded upon the unpredictable behavior of particles on a quantum level, so that 'chance must be elevated to the status of an essential feature of physical behaviour'. ${ }^{21}$ Heisenberg's uncertainty principle soon developed into the Copenhagen interpretation, which extends the principle from the infinitesimal level of quantum physics onto 'the macroscopic objects of sense experience', ${ }^{22}$ based largely on probability in its understanding of physical reality. In order to demonstrate the absurdity of their particular calculated, almost statistical approach to indeterminacy, Schrödinger imagined the by now famed thought experiment of the cat paradox, of which I cite here his full description:

At all events, it [the psi-function] is an imagined entity that images the blurring of all variables at every moment just as clearly and faithfully as does the classical model its sharp numerical values. [...] But serious misgivings arise if one notices that the uncertainty affects macroscopically tangible and visible things, for which the term 'blurring' seems simply wrong. [...] One can even set up ridiculous cases. A cat is penned up in a steel chamber, along with the following device (which must be secured against direct interference by the cat): in a Geiger counter, there is a tiny bit of radioactive substance, so small, that perhaps in the course of the hour one of the two atoms decays, but also, with equal probability, perhaps none; if it happens, the counter tube discharges and through a relay releases a hammer which shatters a small flask of hydrocyanic acid. If one has left this entire system to itself for an hour, one would say that the cat still lives if meanwhile no atom has decayed. The psi-function of the entire system would express this by having in it the living and dead cat (pardon the expression) mixed or smeared out in equal parts.

It is typical of these cases that an indeterminacy originally restricted to the atomic domain becomes transformed into macroscopic indeterminacy, which can then be resolved by direct observation. That prevents us from

for inaccurate measurement or miscalculations, quantum indeterminacy is an essential and necessary uncertainty in our understanding of reality.

21 Peres, 1995, p. 7.

Stapp, 1972, p. 1098. 
so naively accepting as valid a 'blurred model' for representing reality. In itself it would not embody anything unclear or contradictory. There is a difference between a shaky and out-of-focus photograph and a snapshot of clouds and fog banks. ${ }^{23}$

In the cat-paradox experiment, Schrödinger transfers quantitative probability, which he calls the 'blurred model' of superimposing all possible variables (i.e. the cat has an equal chance of being dead or alive, hence it is both), onto the macroscopic and qualitative level of an actual cat in a box, where merely opening the box reveals the cat to be either dead or alive. Though at first sight Schrödinger's condemnation of the out-of-focus photograph appears to contradict Bazin's views on ontogenetic realism, which favors the blurred photograph over the faithful drawing, their argumentations in fact run parallel. In the face of the uniqueness of an irreversible event, unreproducible either as a scientific experiment or in the artificial environment of a studio, both Bazin and Schrödinger condemn the inauthenticity involved in quantitative probability: death, Bazin argues, is 'the qualitative instant in its purest form', ${ }^{24}$ and '"reality" should obviously not be understood quantitatively'. ${ }^{25}$

Such an approach that engages with a statistical mind-set fits within a more general 'epistemological break with traditional notions of determinism $^{26}$ in the earlier days of cinema, which Mary Ann Doane analyzes at length in a chapter called 'Temporal Irreversibility and the Logic of Statistics' in The Emergence of Cinematic Time (2002): 'classical cinema', she writes, 'aligns itself with the logic of statistics as a way of measuring and hence mapping chance events, contingency'. ${ }^{27}$ Like Schrödinger, Bazin appears to reject this probabilistic logic that informs classical cinema as 'the exemplar of temporal irreversibility, as the most effective means of clarifying the idea of an "arrow of time"'. ${ }^{28}$ As Doane points out, the connection between quantitative accumulation and modern technology can be found, for

\footnotetext{
23 Schrödinger, 1983, p. 157.

24 Bazin, 1949c, EC p. 796; Transl. Cohen, 2002, p. 30.

25 Bazin, 1948c, EC p. 354; Transl. Barnard, 2009, p. 228.

26 Doane, 2003, p. 112.

27 Ibid., p. 139.

28 Ibid., p. 117. Bazin's view of authenticity in film provides a particular take on the concept of irreversibility, as it ties in with the idea of an arrow of time through his notion of 'integral realism'. More specifically, it offers us an innovative answer to Zeno's infamous paradoxes, which Doane in another chapter considers constitutive of the emergence of cinematic time, to which I will turn subsequently (see 2.2 Integral Realism: Reality and Cinema 'Ultimately Equal').
} 
instance, in Walter Benjamin's seminal essay 'The Work of Art in the Age of Mechanical Reproduction' (1936), when he writes that:

To pry an object from its shell, to destroy its aura, is the mark of a perception whose 'sense of the universal equality of things' has increased to such a degree that it extracts it even from a unique object by means of reproduction. Thus is manifested in the field of perception what in the theoretical sphere is noticeable in the increasing importance of statistics. $^{29}$

From this perspective, then, mechanical reproduction, Doane argues, 'robs the object of its uniqueness and permanence [as] technical reproduction reduces all things to a common denominator,.$^{30}$ In a comparable manner, ${ }^{31}$ Bazin argues that repeating the event would efface its essence, especially if it involves imminent danger such as a death threat. But the paradox of authenticity does not stop there, since it is only on screen that this qualitative moment (death) can be repeated eternally, amounting to Bazin's ironic adaptation of the medium essentialist notion of 'cinematic specificity'.

\subsubsection{This Is Cinema!}

The fact that many early film theories were concerned with the true nature or the essence of cinema should come as no surprise: film theorists and critics were eager to defend film as a worthy art form by stressing its difference with the other more established arts. As argued in the preceding sections, Bazin, too, was concerned with specifically cinematic traits, such as authenticity, to pinpoint the aesthetics of a filmic image. Yet he does this in the form of a paradox, affirming first and foremost the existence rather than the essence of film: existence precedes essence, the most beautiful film does not exist, and in some cases editing is cinema's negation. From this perspective, death as the final and unrepeatable event

29 Walter Benjamin, 1936; cited in ibid., p. 130.

30 Ibid.

31 On resonances of Benjamin in Bazin, see for instance Dall'Asta's 'Beyond the Image in Benjamin and Bazin: The Aura of the Event' (2011), in which she suggests Bazin's prohibition of montage to formulate an answer to Benjamin's 'Work of Art' essay. Especially relevant in the context of the 'ontological equality' of events on screen is her discussion of Jean Epstein's notion of photogénie in relation to both Bazin and Benjamin's views on montage in film (pp. 5961), to which I will turn later on [see 2.2.1 No Moment Suprême: Bazin Opposes Ellipsis (and Photogénie)]. 
proves, for Bazin as well as for Schrödinger, the authenticity of the event. Such specificity of the event results in Bazin's oxymoronic statement of 'cinematic specificity':

Death is surely one of those rare events that justifies the term, so beloved by Claude Mauriac, cinematic specificity. Art of time, cinema has the exorbitant privilege of repeating it [...] Cinema only attains and constructs its aesthetic time based on lived time, Bergsonian 'durée', which is in essence irreversible and qualitative. [...] I cannot repeat a single moment of my life, but cinema can repeat any one of these moments indefinitely before my eyes. [...] For every creature, death is the unique moment par excellence. The qualitative time of life is retroactively defined in relation to it. It marks the frontier between the duration of consciousness and the objective time of things. Death is nothing but one moment after another, but it is the last..$^{22}$

In Bazin's days, medium specificity was a commonly accepted way of thinking about the objective nature of cinema. However, this framework is fundamentally alien to his understanding of film history: even in his essay on photographic ontology, arguably associated with the notion of medium specificity, Bazin refrains from adopting such a prescriptive framework. His explicit reference to Mauriac in this particular case therefore suggests that he uses this framework to his own advantage: rather than concerning himself primarily with the specificity of photography, a theory that would lead to a priori accepting the authenticity of any filmed event, he instead clearly valorizes the specificity of reality. In so doing, he implicitly supports his argument of cinema as the art of reality rather than that of the image or technology. Thus, by alluding to Mauriac's essentialist view, Bazin here cleverly morphs an argument concerned with medium essentialism into his own valorization of the specificity of the event and cinema's fundamental capacity to repeat irreversibility: 'Dead without requiem, the eternal deadagain of the cinema!'33 From this filmic specificity, which draws cinema to the point of its own annihilation, Daney develops the idea of a 'trip switch' of cinema: 'Bazin indicates the exact spot where the cinema he would not dare dream of becomes a reality and then annuls itself, becomes itself the impossible. This is a limit that is not so distant, whose simple possibility valorises the most banal image: the risk of death for the cameraman, of 
impossibility for the film: "occupational hazards"'. ${ }^{4}$ Daney continues, citing Bazin:

\begin{abstract}
Although the filmmaker sometimes risks death, it can also happen that he may film it without risk or even provoke it by means of his simple presence. The exorbitant power of the camera. You can die just to save face. This is what happened with Valentin, the bird-man (in Paris 19oo): 'This is how it is in this prodigious bird man scene where the poor fool is obviously getting frightened and has finally realized that the bet was idiotic. But the camera is there to capture him for eternity, and he dare not disappoint its soulless eye. If there had been human witnesses, a wise cowardice would certainly have won out (Bazin, 1947).35
\end{abstract}

The death drive of cinema thus functions in two directions that either way involve a certain loss or gain in reality: either the cameraman risks his or her life, or the camera is itself responsible for causing a coward to jump to his death. ${ }^{36}$ Death then becomes the ultimate moment, fundamentally irreversible and irreproducible, when cinema shows its morbid specificity by means of a sacrificial death.

\title{
2.2. Integral Realism: Reality and Cinema 'Ultimately Equal'
}

If the prohibition of editing is first and foremost aimed at countering essentialist theories of film, and bearing in mind Bazin's application of the existentialist maxim 'existence precedes essence' discussed in the previous chapter, then his assertion that the film 'does not exist' is rather problematic, to say the least. In 'Editing Prohibited', however, Bazin offers a way out of this impossibility of film by introducing a 'threshold of trickery' where the myth, which is cinema, both integrates and substitutes for reality:

$[\ldots]$ if what we see on the screen were real and carried out in front of the camera the film would cease to exist, because it would cease thereby to be a myth. It is on the fringes of trick effects, on the margins of the

34 Daney, 1972, p. 37 .

35 Ibid., p. 39 .

$3^{6}$ For the original footage of Frans Reichelt's fatal jump off the Eiffel tower on 4 February 1912 in his attempt to test his so-called 'flying tailor', see: 'Death Jump - Eiffel Tower 1912.' British Pathé. Web. 28.05.2014 <http://www.britishpathe.com/video/death-jump-eiffel-tower/query/ reichelt $>$. 
subterfuge necessary to the logic of the story, that the imaginary is able both to join reality and to replace it [à la fois d'intégrer la réalité et de s'y substituer]. ${ }^{37}$

This simultaneous integration of and substitution for reality should be taken quite seriously, as it provides a reformulation of traditional film theoretical issues via the notion of 'integral realism', which is a guiding principle in Bazin's work. In what follows, I hope to demonstrate the ways in which Bazin overrides this insoluble dilemma between image and reality by seeing both in a Newtonian sense as 'ultimately equal'. By analyzing in Bazin's writing, as well as Daney's interpretation of Bazin, a series of mathematical and philosophical references, such as the ellipsis/ellipse, the asymptote and quantitative measurements versus qualitative leaps, I argue that Bazin's proposition for 'integral realism' is to be understood not in the sense of a complete substitution or total illusion of reality but rather in mathematical terms as an integral calculus: an approximation and measure of reality. With this, Bazin held an entirely different and original view on the relation between art and reality: he situates himself explicitly against the essentialist approach to film art from the silent film theorist Jean Epstein (1897-1953), and more implicitly reformulates basic principles of the documentary in the work of Roger Leenhardt (1903-1985).

\subsubsection{No Moment Suprême: Bazin Opposes Ellipsis (and Photogénie)}

Bazin's solution for the dilemma between image and reality lies in his firm acknowledgement of the ontological equality of instants, in reality as well as on screen. This view, both canonical and highly original, comes to the foreground in his praise of Italian neo-realism, which he considered 'the great event of post-war cinema' ${ }^{3}{ }^{8}$ For him, neo-realism provided a victorious new solution to post-war aesthetic conflicts by creating a new kind of image, which he calls the image-fait:

[...] a fragment of raw reality, inherently multifacious and ambiguous, whose 'meaning' becomes apparent after the fact, through other 'events', connected up in our minds. Rossellini undoubtedly chose these events [faits] wisely but while respecting their integrity as events [faits]. [...] The nature of an 'image-event' [image-fait], however, is not simply to connect 
with other 'image-events' [images-faits] in ways invented by our minds. This in a sense is the centrifugal nature or the image, which makes it possible to create a narrative. Because each image, seen on its own, is only a fragment of reality and exists prior to its meaning, the entire surface of the screen must have the same concrete density. ${ }^{39}$

The premise of ontological equality prevents him from adopting theories of film that claim cinema to be either more or less than reality. As I will argue, within the context of medium specificity, Bazin's notion of image-fait opposes the former view as crystallized in Epstein's concept of the photogénie, while the latter solidifies in Roger Leenhardt's assertion of cinema as the art of ellipsis. In both cases, Bazin's notion of integral realism supports the existentialist rather than an essentialist view on film.

Bazin's implicit criticism of unequal treatments of moments in the context of medium essentialism becomes most apparent in a passage in Daney's reading of the prohibition of editing, in which he concerns himself with a 'way out' of this trip switch of an impossible cinema:

In 'classic' cinema, transformation as the result of a quantitative accumulation without a qualitative leap, as a new state always given but never produced, is resolved or rather it does not get resolved.

- Either there is no transformation

- Or it occurs as a teleological coup.

[...] Representation is no longer the condition for a good exfoliation of the story but a sort of travesty that can say nothing about the nature of things, about their heterogeneity or the laws of their mutations. ${ }^{40}$

Daney conceives classical representation in cinema as a travesty, a distorted reproduction that effaces the true nature of the event, and stresses in a remarkably Kierkegaardian fashion ${ }^{41}$ the importance of a 'qualitative leap'

39 Ibid., EC p. 358; Transl. Barnard, 2009, pp. 241-242, slightly modified. [Barnard drops Bazin's '...'; also, Bazin's own image-fait is more accurate than 'event', cf. his stance against the notion of dramatic events.]

40 Daney, 1972, pp. 39-40.

41 In his Concluding Unscientific Postscript (1846), Danish philosopher and theologian Søren Kierkegaard maintains that transformation from one state to another happens only by means of a qualitative leap, and that those two states cannot exist simultaneously. The qualitative leap of faith relates to Kierkegaard's view on the accidental nature of historical events, where possibility turns into actuality: 'The whole point of the historical, for Kierkegaard, is that it constitutes the realm of "becoming" that makes intelligible the movement from possibility to actuality, a movement that remains impossible within the realm of necessity' (see: Michalson, 
over 'quantitative accumulation': that which makes something happen is the leap from possibility into actuality. Beyond the implicit references to statistics, as seen previously with Benjamin, and accordingly the outspoken preference of the qualitative instant over quantitative probability, which supports Bazin's authenticity argument, Daney here extracts a twofold criticism that is contained in Bazin's ironic affirmation of cinematic specificity. Essentially, both options relate to a different understanding of cinematic specificity, either viewing film as an abstract (option 1) or a surplus (option 2) of reality. In order to set the ground for a novel understanding of 'integral realism', I will discuss both these points that the image-fait opposes, as crystallized respectively in terms of the ellipsis and photogénie.

Daney's first point of criticism in classical narration, namely that nothing ever happens, resonates with the age-old philosophical paradox of motion stipulated by Zeno of Elea (490-430 BC), who derived from an infinitesimal division of distance that motion itself is impossible: Achilles will never surpass the tortoise and the arrow is in fact motionless. In The Emergence of Cinematic Time, Doane argues that 'Zeno's fallacy finds its technological embodiment in the cinema - in its spatialization of time, its investment in the reality of instants. ${ }^{42}$ Doane posits two main interpretations of the paradox in relation to film theory: Bergson, from his side, upheld that 'movement slips through the interval ${ }^{43}$ and that therefore cinema can only give an illusion of movement, while Epstein, who dispersedly references Zeno's paradox in his writing, argues altogether that cinema ultimately shows Zeno's false reasoning to be accurate: a succession of still images creates movement through flickering light. ${ }^{44}$ In this manner, Epstein solves what

1979, p. 330). Bazin, from his side, indeed implicitly takes on this dynamic in his discussion of cinematic montage: '[...] on pourra remarquer à fort juste titre que si Ballon Rouge ne doit rien essentiellement au montage, il y recourt accidentellement [emphasis in original]' (Bazin, 1953-1957, EC p. 2566): '[...] if The Red Balloon owes essentially nothing to editing, it resorts to it fortuitously.' (Transl. Barnard, 2009, p. 79) [Barnard drops the emphasis on 'essentiellement' and 'accidentellement' and loses the implied opposition between essence and accident.]

42 Doane, 2003, p. 174.

43 Ibid.

44 On numerous occasions, Epstein references Zeno's paradox, for instance in 'Intelligence of a Machine' (1946): 'One breaks a window, counts the pieces and declares: this window was composed of four triangular, two quadrangular, six pentagonal pieces and so on. This is the model of the false reasoning of all atomic theory, which is, besides, very similar to Zeno's reasoning' (Epstein, 1946, p. 264). And again: 'the cinematograph appears as a mechanism mysteriously destined to the expertise of the false accuracy of the famous reasoning of Zeno about the arrow, to the analysis of this subtle metamorphosis of rest in mobility, of the emptiness in fullness, of continuity in discontinuity - a transformation that staggers as much as the generation of life out of the inanimate' (Ibid., p. 26o). 
he calls the 'insoluble problem', the 'irreconcilable contradiction', which Bergson upholds, by asserting that continuity and discontinuity, movement and interruption are not incompatible but rather 'two modes of unreality that are easily interchangeable. ${ }^{45}$

In his quest for the essence of cinema, which he saw crystallized in the close-up as 'the soul of cinema', ${ }^{46}$ Epstein radically sought a surplus of reality on screen, which he conceptualized in his notion of photogénie:

I would describe as photogenic any aspect of things, beings, or souls whose moral character is enhanced by filmic reproduction. And any aspect not enhanced by filmic reproduction is not photogenic, plays no part in the art of cinema. ${ }^{47}$

Epstein's photogénie could not be further removed from Bazin's image-fait; in fact, it appears to me as though Bazin developed his argument with Epstein's film theory in the back of his mind. In an analysis of Paisà (Roberto Rossellini, 1946), Bazin indeed opposes the image-fait to the shot and the close-up, in which Epstein had found the essence of film:

The unit of Paisà's narrative is not the shot, with its abstract perspective on the reality being analysed, but the event $[$ fait $]$. [...] In Paisà (and by this I mean, to varying degrees, most Italian films), close-ups of doorknobs are replaced by the image-event [l'image-fait] of a door, all of whose concrete qualities are equally visible. ${ }^{48}$

Bazin's dissatisfaction with the close-up as a tool in cinematographic narrative as well as Epstein's essentialist notion of photogénie reflects Daney's second point of criticism, the 'teleological coup': an unequal organization of events that cannot convey the concrete density of reality on screen.

But the teleological critique in Daney's phrasing suggests yet another, intrinsically related approach to film that Bazin appears to oppose, namely that in the process of abstraction, cinema itself 'slips through the interval'. Following French filmmaker and editor Roger Leenhardt who shared many ideas 
on realism with Bazin, ${ }^{49}$ this interplay, which borders on the in-existence of cinema itself, is often referred to as the 'elliptical' nature of film:

When Leenhardt claims that the primary figure of cinema is the ellipsis not the metaphor, he is insisting that cinema is not a symbol system substituting one set of signs for another (as classic film aesthetics believed), but an always partial view of something significant that tries to appear through it. ${ }^{\circ}$

In his views on documentary authenticity epitomized by the shark attack, Bazin comes close to affirming Leenhardt's claims, and indeed Andrew argues that '[ellipsis] stands as the key technique necessary for the very operation of the documentaire, that genre of film he [Leenhardt] was proud to practice'. ${ }^{1}$ But while Andrew stresses the similarities between their assertion of 'primordial realism', $5^{2}$ he nuances this connection when it comes to the notion of the ellipsis and argues that Bazin understands it differently.

[I] $\mathrm{t}$ is time that Bazin, following Bergson, treats as pre-existent, time that extends before and after the spatial designs that humans construct. His feel for the integrity of time explains Bazin's hesitancy about ellipsis [...]. Ellipsis does violence to the continuity of nature that the camera respects in its 'take'. [...] On the one hand, ellipsis derives from the condition that keeps us from knowing everything; on the other, ellipsis organizes experience to suit our needs and projects; writers and filmmakers deploy it systematically for their 'plots' as they pare away what they deem inessential. Ellipsis is the temporal equivalent of framing. And framing, Bazin asserts, can only be provisional in the cinema, a medium sensitive like

49 Bazin and Leenhardt both uphold a counter-determinist view on film history following the advent of the talking film, which would become so prevalent both in Bazin's proclamation of realism and his prohibition of montage. As Andrew writes in 'A Film Aesthetic to Discover', 'For both men, the existence of sound changed the essence of cinema [emphasis in original]' (Andrew, 2007, p. 57).

50 Andrew, 2013, p. 25.

$5^{1} \quad$ Andrew, 2007, p. 58.

52 Ibid., p. 59. On Leenhardt's notion of 'primordial realism', see also Joubert-Laurencin, 2014, pp. 30-32. While he maintains that '[...] Bazin will entirely transfer that which is, in Leenhardt, still a stylistic description based on a literary trope, onto the theoretical definition of a cinematographic mechanization' (p. 31), I hope to demonstrate that Bazin distances himself from Leenhardt's literary trope and instead seeks in natural sciences, in particular the work of Isaac Newton, a proper framework for his argument of cinema as the art of reality. 
no other to what lies beyond the edges of the screen in the infinite and unknowable volume (and continuity) of space-time. ${ }^{53}$

Here, the narrative abstraction in ellipsis is dismissed as a dramatization of the proportional analysis of reality, i.e. the close-up; again, this comes down to Bazin's notion of image-fait which he describes as including 'the centrifugal nature of the image, which makes it possible to create a narrative'. ${ }^{54} \mathrm{By}$ evoking cinema's 'centrifugal properties', a recurring reference to Newtonian physics in Bazin which I will discuss at length later on (see Section 3.2. Cinema and Painting), Bazin again implicitly rejects Epstein's essentialist mind-set, as it denies not only the universal equality of moments (photogénie) but also the fundamental laws of nature that cinema, according to Epstein, destroys:

The non-contradiction ceases to be a valid criterion of truth. Zeno's arrow, which is immobile in flight, does not surprise us anymore. Any being combines movement and stillness, solidity and fluidity, languor and precipitation, tininess and immensity according to space-time conventions, where the lens arbitrarily places that being. Had the neurotic Pascal seen a few films, he would have had to find a new support to this anguish other than the size differences between mite and man - a difference that cinema can cancel or reverse at will, like the most banal optical illusion..$^{55}$

Unlike Epstein's approach, which stresses the difference between cinema and reality, Bazin's entire ontological project, his view of cinema as the art of reality, is firmly embedded in an acknowledgement of cinema's offscreen origins, in reality. Unlike Epstein, Bazin reaffirms rather than rejects the pascalian 'double infinity', which views the universe as 'an infinite sphere, the centre of which is everywhere, the circumference nowhere'. ${ }^{6}$ In this manner, his rejection of both photogénie and ellipsis gives way to a centrifugal understanding of l'image-fait. Accordingly, Bazin's notion of 'integral realism' adheres to the laws of nature. The most striking example of this sort in Bazin's writing, is his occasional reference to the calculus, as it was stipulated by Isaac Newton in Lemma II of his Philosophiae Naturalis Principia Mathematica (1687). ${ }^{57}$

Andrew, 2012, p. 128.

4 Bazin, 1948c, EC p. 358; Transl. Barnard, 2009, p. 242.

55 Epstein, 1947, p. 32; Transl. Nguyen, 2012, p. 332.

56 Pascal, 1670 , p. 16-17.

57 Though Newton had already started developing calculus in Methods of Fluxions (1671), it remains historically unclear whether Newton ultimately was its sole and independent inventor, 


\subsubsection{Bazin on Umberto D: Reformulating the Pregnant Instant}

In order to fully grasp Daney's criticism in the context of the discussion on editing and cinematic specificity, it is important to recognize in it the subtle references to parts of Bazin's essay on Umberto $D$, in which the ellipse is understood as 'the moving conclusion to a dramatic series of events [emphasis in original]': $5^{8}$ the 'teleological coup' in Daney's formulation. Bazin puts this in plain words in an essay on Umberto $D$ (Vittorio De Sica, 1952), when he praises Cesare Zavattini's scenario for following precisely the opposite of ellipsis:

The cinema here is conceived as the exact opposite of that 'art of ellipsis' to which we are much too ready to believe it devoted. Ellipsis is a narrative process; it is logical in nature and so it is abstract as well; it presupposes analysis and choice; it organizes the facts in accord with the general dramatic direction to which it forces them to submit. 59

Bazin here rejects Leenhardt's elliptical approach to narrative form, as this would imply a considerate selection of events in which seemingly irrelevant or meaningless moments are eliminated to emphasize others that weigh more on the course of events. ${ }^{60}$ Instead, by acknowledging the double meaning of l'ellipse in French, both referring to the stylistic figure as well as the geometrical concept of the conic section, I argue that Bazin's system enables a subtle but consequential change of paradigm from linguistics to analytical mathematics. As Andrew already suggested, in its temporal abstraction, the stylistic figure of an ellipsis, the cut, in some way relates to that 'infinite and unknowable volume' of the three-dimensional volume, by which Bergson conceives his famed spatialization of lived time in Matter and Memory (1896). Ultimately, the discussion of editing, then, brings us to the heart of the insoluble dilemma

or whether the final and complete publication of his methods in 1704 had been circumstantially influenced by Gottfried Leibniz, who had started working on a similar method in 1674 which he then published before Newton's completed work on calculus. Essentially, this quarrel is irrelevant for the current debate on integral realism, but since Bazin also points to Newtonian physics when he declares the screen as centrifugal and fundamentally opposed to the centripetal frame of painting, it is fair to assume that here, too, Bazin finds in Newton a fitting framework to develop his views on film.

58 Bazin, 1952a, EC p. 1024; Transl. Gray, 2005, p. 80.

59 Ibid., EC ibid.; Transl. Gray, 2005, p. 81.

60 As Jean-François Chevrier points out in 'The Reality of Hallucination in André Bazin', Bazin makes a mistake and conflates two kitchen scenes into one, which he would in 1953 support, quite ironically, as being anti-elliptical (Chevrier, 2011, p. 48). 
between continuous reality and its abstraction - a dilemma that Bergson maintains (cinema is less) and Epstein dissolves (cinema is more).

From his side, Bazin answers to the dilemma without having to reject either reality nor the image, by means of a method that, to use Bazin's formulation, allows 'both to join reality and to replace it ${ }^{6}{ }^{1}$ The bridge he builds, I argue, between image and reality is essentially similar to the one Isaac Newton lays between the continuous curve and its infinite approximation in discrete units, which he establishes in the fundamental theorem of calculus. Newton originally developed calculus as a method to enable calculating a curvilinear volume by dividing it into discrete, measurable units (Fig. 5), and in so doing he provided an ingenious countermand to the age-old paradox of Achilles and the tortoise. Lemma II of his Principia explains the basic reasoning supporting the first theorem of integral calculus:

If any figure AacE, comprehended by the straight lines Aa and $\mathrm{AE}$ and the curve acE, any number of parallelograms [...] are inscribed upon equal bases [...]: if then the width of these parallelograms is diminished, and their number increased indefinitely, I can say that the ultimate ratios which the inscribed figure AKbLcMdD, the circumscribed figure AalbmcndoE, the curvilinear figure AabcdE have to one another are ratios of equality. [...]

$[T]$ he inscribed figure and circumscribed figure and, all the more, the intermediate curvilinear figure become ultimately equal to each other. ${ }^{62}$

By dividing the curvilinear space into a number of parallelograms, and the more this number reaches infinity, the sum of these discrete units will ultimately equal the space enclosed by a continuous curve. Similarly, I argue, Bazin's notion of 'integral realism' postulates that cinema can be ultimately equal to reality; the ever-increasing frame rates in contemporary film, even the perfecting resolutions of digital cinema transferred into a thickening pixelation, can be said to proceed from this Newtonian logic, which Bazin is the first to apply to film in his praise of Italian neo-realism.

In the essay on Umberto $D$ specifically, Bazin takes up the Newtonian framework $^{63}$ as he sees the narrative development alongside reality as a succession of 'concrete instances' that are all 'ontologically equal':

61 Bazin, 1953-1957, EC p. 2566; Transl. Barnard, 2009, p. 80.

62 Newton, 1999, p. 433.

63 See also Dalle Vacche, 2016, who takes a different, bergsonian approach to the mathematical references in Bazin's work on Italian neo-realism. 


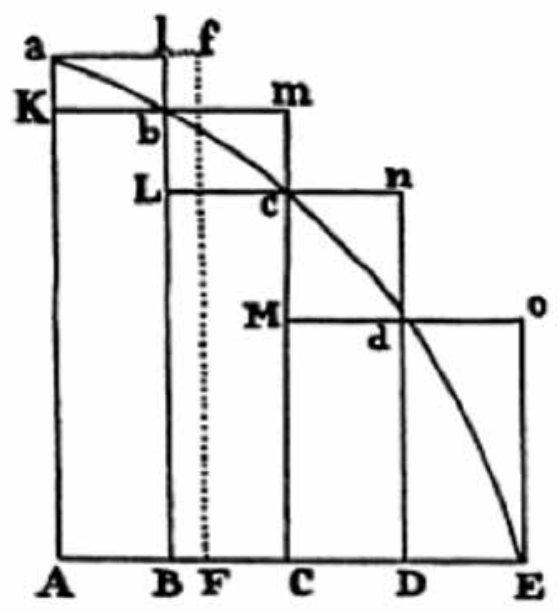

Fig. 2 Newton's calculus, 'ultimately equal'

If one assumes some distance from the story and can still see in it a dramatic pattern, a single general trend in its component events, this is only after the fact. The narrative unit is not the episode, the event, the sudden turn of events, or the character of its protagonists; it is the succession of concrete instants of life, no one of which can be said to be more important than another, for their ontological equality destroys drama at its very basis. [my emphasis] ${ }^{64}$

He further develops the implicit interest in calculus most clearly in his remarkable analysis of the wake-up scene in Umberto $D$ :

De Sica and Zavattini attempt to divide the event up in still smaller events and these jump to events smaller still, to the extreme limits of our capacity to perceive them in time. Thus, the unit of event in a classical film would be 'the maid's getting out of bed'; two or three brief shots would suffice to show this. De Sica replaces this narrative unit with a series of 'smaller' events: she wakes up; she crosses the hall; she drowns the ants; and so on. But let us examine just one of these. We see how the grinding of coffee is divided in turn into a series of independent moments; for example, when she shuts the door with the tip of her outstretched foot. As it goes in on her the camera follows the movement of her leg 
so that the image finally concentrates on her toes feeling the surface of the door. ${ }^{65}$

If one were to follow either the elliptical or photogenic logic, perhaps a close-up of Maria's hand on her belly might have sufficed to reveal her pregnancy to us, but instead the scene develops through a series of both temporally and spatially infinitesimal units: from the bedroom, through the hallway, into the kitchen, the matches, the ants and the water, the chair, the door, her foot, her toe (Fig. 3-8).

By now we know of Maria's pregnancy, and yet everything appears to follow her everyday routine. This idea is reinforced when she first tells Umberto D. of her secret:

Maria: Have you seen all the ants? Mr. Umberto, can you see anything? Umberto D.: No, nothing.

M.: You can, a little. Did you know I'm pregnant?

U.D.: My god! And you just say it like that?

M.: How do you want me to say it?

The revelation of Maria's pregnancy becomes no more than the ants on the wall, which are, by the same token, of no lesser importance than the heavy memory of wartime. In his analysis of this sequence, Jean-François Chevrier points out that during WWII, Zavattini had compared the overwhelming sight of war spreading with an ant-infested kitchen: 'War seems more formidable when you aren't in the middle of one. Ants have overrun a wall in the kitchen; they march along in a way that reveals their certainty that I won't discover their nest. ${ }^{66}$ While Chevrier sees the close-up of the ants in the sink as relating to Epstein's photogénie, I believe that, given the explicit references to limits and infinities in Bazin's analysis, De Sica's usage of close-ups is better served by the notion of image-fait, which opposes Epstein's unequal treatment of moments as well as his rejection of pascalian double infinity.

In the same way that death on screen, which is 'nothing but one moment after another', best illustrates Bazin's notion of cinematic specificity because 'it is the last', ${ }^{6} 7$ its opposite, pregnancy, follows the rule of ontological equal-

65 Ibid.

66 Cesare Zavattini, cited in Chevrier, 2011, p. 51.

67 Bazin, 1949c, EC p. 796; Transl. Cohen, 2002, p. 30; Bazin does not discuss pregnancy as such, but he compares the uniqueness of death to love, sex specifically: 'Yet two moments in life radically escape this concession to consciousness: sex and death. Both are in their own way 

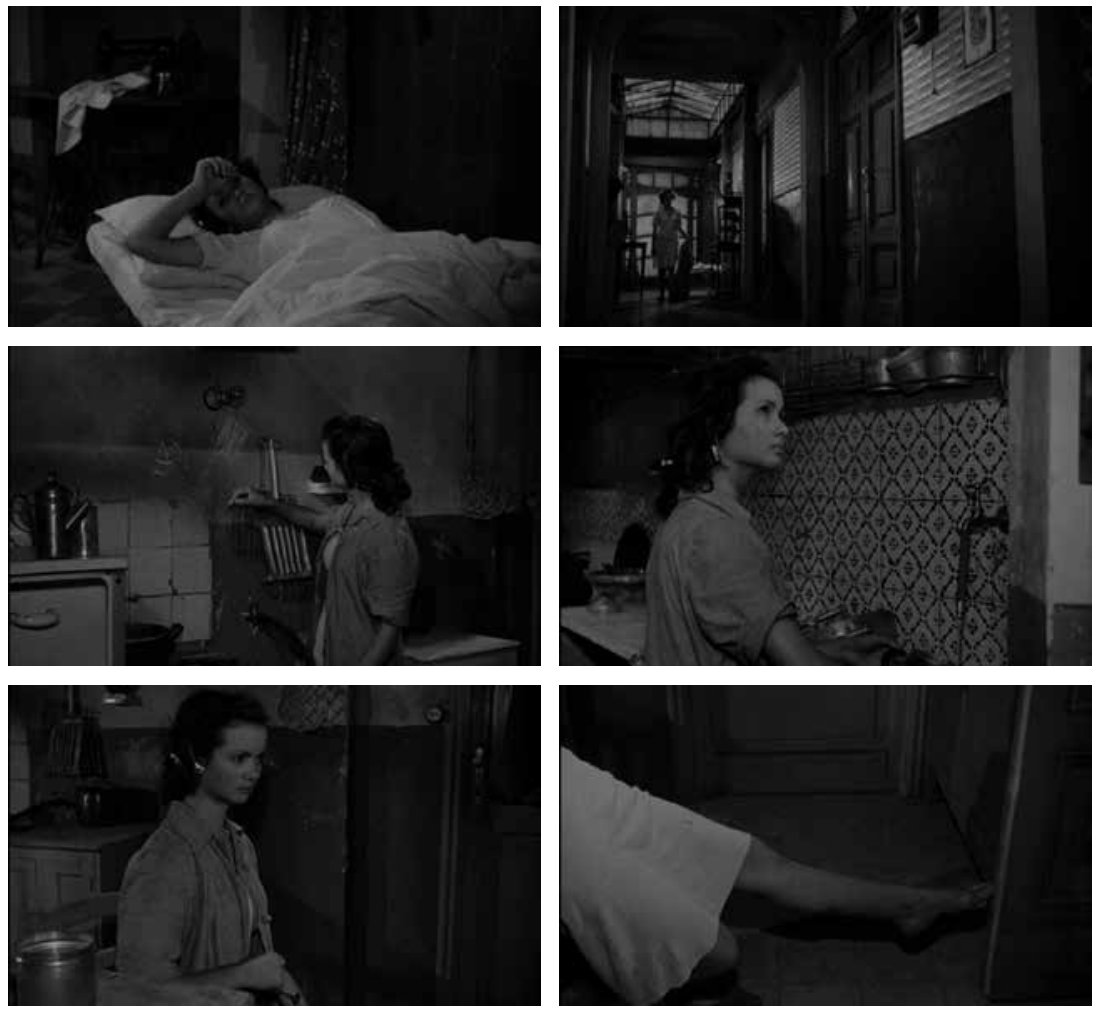

Fig. 3-8 Morning routine, a division of instants

ity. In this manner, the essay on Umberto $D$ offers itself as an original take on what Jacques Aumont, following German philosopher and art critic Gotthold Lessing, discusses in terms of a 'pregnant instant':

A painter, whose means are spread out in space, does not need to worry about time, but about choosing an instant, or the skilful deduction of the best instant, the most significant, the most typical and the most 'relevant' [le plus pregnant]. ${ }^{68}$

The 'pregnant instant' in art history stands precisely for the prevalence of one moment over any other; we can see clearly that the photogenic

the absolute negation of objective time: the qualitative instant in its pure state. Like death, love is lived and cannot be imagined [ne se représente pas] [...]' (ibid.).

68 Aumont, 1989, pp. 75-76. [Pregnant in French also means 'meaningful', which Aumont links to grossesse, pregnancy in English.] 
moment would appear too centripetal and painterly for Bazin. Moreover, Aumont remarks that this instant 'does not exist in reality', ${ }^{69}$ when he describes it, following a rather familiar train of thought, as an oxymoron: 'One can only harmonize instantaneity and relevance [la prégnance], the authenticity of the event with its significant charge, at the expense of a trick. ${ }^{70}$ Similarly, Bazin takes precisely the scene from Umberto $D$ that reveals the pregnancy as a challenge to the conventional 'unité-événement' of classical narration.

This is, I would argue, an important point in Bazin's view on cinema and its relation to reality. Since pregnancy, like death, is itself a life-changing event, but mostly because, unlike the finality of death, it announces a beginning, the analysis of Umberto $D$ ultimately makes a strong case for the existence of film in accordance with 'the laws of mutations' that frame Daney's reading of Bazin. In this manner, Bazin understood Italian postwar cinema to be a new realism, in which 'the need for narrative is more biological than dramatic in nature. It buds and grows with the verisimilitude of life itself' ${ }^{11}$

\subsubsection{The Asymptote of Reality: Reality $\simeq$ Cinema}

At the end of his essay on Umberto $D$, Bazin himself solidifies the implied mathematical mind-set as he introduces almost conjecturally his oft-cited suggestion of cinema as the asymptote of reality:

De Sica and Zavattini are concerned to make cinema the asymptote of reality - but in order that it should ultimately be life itself that becomes spectacle, in order that life might in this perfect mirror be visible poetry, be the self into which film finally changes it [Telle qu'en elle-même enfin, le cinéma la change $].^{72}$

In analytic geometry, an asymptote is a straight line to which a curve tends at infinity, but which it never crosses. From this point of view, an elliptical figure in fact has no asymptote, so when Bazin then proposes to consider cinema as the asymptote of reality, the distance he takes from Leenhardt's literary trope is rather radical. Bazin is clear in assigning to cinema the role of

71 Bazin, 1948c, EC p. 356; Transl. Barnard, 2009, p. 234.

72 Bazin, 1952a, EC p. 1024; Transl. Gray, 2005 p. 82. 
the asymptote, the straight line, which implies, following the mathematical logic, that it is reality that ultimately tends to cinema and that therefore, such as into itself, finally, cinema changes reality.

The enigmatic closing line to this article is one of many bazinian reformulations, this one taken from Stéphane Mallarmé's The Tomb of Edgar Allan Poe (1877), which he repeats about eleven times throughout his writing: 'Tel qu'en lui-même enfin l'éternité le change.73 In this specific instance, Bazin reuses the phrase to conclude a discussion on narrative progression without teleological coup, in which cinema shows reality as poetic. In an essay entitled 'William Wyler, or the Jansenist of the Mise-en-scene', Bazin repeats the poetic potential of integral realism:

There is a kind of 'cinema' that is like poetry. It is madness to see cinema as something isolated that can be set down on a piece of celluloid and projected on a screen through an enlarging lens. [...] Cinema is not some sort of independent matter whose crystals must be isolated at all costs. It is, rather, matter in an aesthetic state, a form of narrative entertainment. ${ }^{74}$

It is not coincidental, then, that in the essay on Wyler, Bazin praises what he calls a 'realist ethics' as a style without style ${ }^{75}$ against the mannerist style of others (Capra, Ford, Lang). ${ }^{76}$ Bazin here again finds a fitting comparison with mathematics, as he concludes that 'a film's purity, or better yet, to my mind, its cinematic coefficient should be calculated by the effectiveness of the way its scenes are conceived'.77 From this poetic potential, Hervé Joubert-Laurencin reads Bazin's reformulation as recalling his ontological foundation of film in the 'mummy complex':

If one recalls that for Bazin, in his first essay, 'cinema is the mummification of change', it becomes evident that this formula substitutes for theory:

See Joubert-Laurencin's analysis of this precise phrase: Joubert-Laurencin, 2014, pp. 153-158.

75 Ibid., EC p. 373; Transl. Barnard, 2009, p. 46: 'The only way to imitate Wyler would be to adopt the ethic of his mise en scène [...] There can be no imitators of Wyler, only disciples.'

76 By supporting a certain anti-mannerist aesthetics, Bazin here indirectly aligns himself with the Jansenists of Port-Royal (and he does this obviously in the title of his essay), a Christian theological movement that upheld original sin and divine grace and with which Pascal associated himself. On Pascal and mannerism, see Gheeraert, 2006, pp. 285-305.

77 Bazin, 1948d, EC p. 389; Transl. Barnard, 2009, p. 67. [Barnard translates 'coefficient' into 'quotient', which is a different mathematical concept.] 
to change nothing (to the adjacent world) to change everything (making a film = changing the world) is the maxim of ontological realism at its purest reformulation of classical mimesis. $^{78}$

Moreover, upon closer examination the line borrowed from Mallarmé summarizes the mathematical metaphors by which Bazin conceives the reality versus image dilemma: cinema takes the place of eternity or infinity - the asymptote - which continuous reality (Bergsonian durée), taking the place of the poet, approaches.

As a tentative answer to the insoluble dilemma between image and reality, embedded in Bazin's reformulation of cinematic specificity, James Tweedie understands the asymptote-analogy to mean that cinema 'brackets off' the flux of reality and links it to 'the foundational premise of [Alain] Badiou's system of thought [based on] modernity's "laicization" of the infinite'.79 He writes:

Film can enclose that infinite expanse momentarily in a frame whose closest physical analogies he saw as the window and the mirror - Bazin cycles through these familiar comparisons, seemingly unsatisfied with all of them - but whose closest conceptual analogue may be the provisional brackets of a mathematical set formed under specific conditions. ${ }^{80}$

Yet, Tweedie appears to turn the analogy around, seems to view reality as the asymptote and consequently rids cinema of its transformative power. Instead, as I have established, with concepts like the asymptote, integration and substitution, Bazin pushes the mathematical analogy beyond the contingency of set theory, against the backdrop of infinity and eternity: $\int$ not $[\ldots, . .$.$] . Rather than initiating a laicization of infinity, then, Bazin's integral$ realism, like Newton's calculus, does not solve the dilemma between image and reality. As I have argued, it maintains this difference as insoluble: a paradox.

Reality is not art and art is not reality, but in the cinema they are ultimately equal. It is not a coincidence, then, that in any serious attempt at explaining Bazin's realism, one needs to invoke inherent contradictions, such as Zeno's paradox of the tortoise or Schrödinger's cat paradox, because the very existence of film, at least for a realist like Bazin, ultimately involves 
its own impossibility (ultimate reality, no more film). In the final part of this chapter, I will approach the realist paradox from a more philosophical perspective as a wager: as with flipping a coin, cinematic realism involves risk, loss and gain.

\subsection{Bazin's Wager}

On numerous occasions, Bazin adheres to a paradigm of choice, as his views on cinematic realism appear to derive from the conviction that one cannot have both, for instance, authenticity and figuration. Schrödinger's cat cannot be both dead and alive - we cannot depict a shark attack as well as real danger. Instead, his discussion of sharks on screen is built around a certain pragmatism, where a gain in reality implies the loss of its qualities of resemblance. As such, the hesitating between the real shark and a substitute dummy in the film history of sharks perfectly lends itself to the 'I know, but all the same' paradigm, around which Daney reads Bazin's prohibition of editing:

Bazin [...] always oscillated between 'I know it' and 'but all the same'. At times, he clearly sees the realization of cinema's essence - aided by technique - in its move toward greater and greater realism: this is his famous 'gain in reality'. At other times, when he is reader to acknowledge his own fantasy, he points out that for every gain in reality there is a corresponding loss of reality' in which abstraction insidiously returns. ${ }^{81}$

Daney extracts on the one hand a 'risk function', i.e. the probable cost associated with greater realism, and on the other hand an expected value, a hoped-for gain that is worth the cost associated with it. It is no coincidence that Daney constructs the realist argument in terms of a wager. In fact, this paradigm of loss and gain pervades Bazin's thought process to such an extent that one could conceive his work on documentary authenticity, cinematic specificity and editing altogether as a realist wager.

\subsubsection{Calculated Risk}

This chapter brought forth two tentative equations:

1. $\quad$ editing $=$ probability, and

2. event $=$ authenticity. 
But it would be all too easy to rank Bazin under the latter only: both are indeed diverging approaches to reality (quantitative versus qualitative), yet they are two sides of the same coin. Bazin's prohibition of editing, too, is only one side of the realist coin: in 'Death Every Afternoon', a critical review of Bullfight (Myriam Borsoutsky \& Pierre Braunberger, 1951), he praises Myriam Borsoutsky's editing technique precisely because, in some cases, 'it is an essential element in the film's creation'. ${ }^{82}$ The essay's title is an obvious reference to Ernest Hemingway's Death in the Afternoon (1932), and for good reasons. The article as well as the book deal, of course, with bullfights: Hemingway wanted to convey 'the feeling of life and death's3 based on personal experience, Bazin admits 'never [having] been to a bullfight [...] but [the film] gives me its essential quality, its metaphysical kernel: death, ${ }^{84}$ Both authors also implicitly or explicitly deal with editing. Compare these two citations:

the art of bullfighting, which is only kept from being one of the major arts because it is impermanent, in the arrogant slowness of his veronicas becomes, for the seeming minutes that they endure, permanent. ${ }^{85}$

Hemingway sees slow motion in the torero's tense movement, described here as a 'veronica' - a term referring to the basic starting position of a bullfighter but also a metaphor Bazin uses throughout his texts to describe the cinema screen. ${ }^{86}$ Now Bazin:

This is why the representation on screen of a bull being put to death (which presupposes that the man has risked death) is in principle as moving as the spectacle of the real instant that it reproduces. In a certain sense, it is even more moving because it magnifies the quality of the original moment through the contrast of its repetition. It confers on it

82 Bazin, 1949c, EC p. 795 .

83 Hemingway, 1932, p. 3.

84 Bazin, 1948d, EC p. 795 .

85 Hemingway, 1932, p. 12.

86 See, Bazin, 1945; Bazin, 1953-1945; Bazin, 1951a. Interestingly, Sergei Eisenstein is the first to interpret the official term metaphorically in his drawings of bullfighting in Mexico, dating from 1931 to 1932: at least two of these drawings show the bull's head in true iconic fashion imprinted on the torero's veil. See also François Albera's “'The Heritage We Renounce": Eisenstein in Historiography.' In: Sergei M. Eisenstein: Notes for a General History of Cinema. Eds. Kleiman, Naum \& Antonio Somaini. Amsterdam: Amsterdam University Press (2016): p. 275 . 
an additional solemnity. The cinema has given the death of Manolete [a famous matador who died during the fight] a material eternity.

On the screen, the toreador dies every afternoon. ${ }^{87}$

Or again, specifically relating to editing, Hemingway suggests that a first visitor should choose:

[...] a seat not too near the ring so that he will see the entire spectacle rather than, if he is too close, have it constantly broken up into bull and horse, man and bull, bull and man - and a hot sunny day. ${ }^{88}$

In other words, having to turn your head from the bull back to the torero in a real-life experience lines up with what in cinema would be an editing sequence such as a shot reverse shot or a close-up inserted in a long shot (which, in turn, would be the distant seating of Hemingway's spectator). Needless to say, Borsoutsky's Bullfight is full of editing techniques and montage sequences, but instead of rejecting them as cutting up the action, Bazin praises the freeze frames and especially its matches on action: "Without us noticing the switch, a "veronica" beginning with one matador and bull ends with a different man and a different animal. ${ }^{89}$ His discussion of neo-montage, as he calls it, goes well beyond the traditional Kuleshov effect: ${ }^{90}$ here, ' $\mathrm{t}$ ] he linkage of two bulls in a single movement does not symbolize the bulls' strength; it surreptitiously replaces the photo of the non-existent bull we believe we are seeing'. ${ }^{91}$ Like the torero fighting off the bull with his cape, the editor's job is risky business, directing the action through cuts and pastes while having to preserve its 'metaphysical kernel'. One might think an editor in the editing room is safer than the torero in the ring. Yet the analogy is fair, as bullfighting rarely involves the death of a torero: following the strict rules of the game, the bull will certainly die..$^{2}$

87 Bazin, 1948d, EC p. 796.

88 Hemingway, 1932, p. 13.

89 Ibid., p. 28.

9o The Kuleshov effect illustrates that the meaning of an image in a montage sequence is derived from the images that precede and proceed it: the expressionless face of a man on screen will look hungry when it follows the image of a bowl or soup, or sad when it follows that of a child's corpse. Bazin's notion of 'neo-montage' moves in a different direction: rather than suggesting (or symbolizing) meaning via the combination of two shots, Myriam's cut substitutes for the shots we cannot see.

91 Bazin, 1948d, EC p. 795 .

92 Once a bull enters the ring, it will certainly die. If it were to get the upper hand at the torero, other toreros would immediately take over, or a picador on horseback will put the animal down. And if the bull does win, it is killed afterwards anyway: a winning bull, Hemingway writes, 
There is a risk, of course, but it is calculated: the skills of the torero should bring the fight to the very limit, enraging the bull to the extent that it will continue its attack, yet without really reaching equal risk for man/animal (that would simply be foolish). Similarly, an editor should choose his or her cuts and 'movements' carefully, pushing the ongoing trickery to its extreme. From this perspective, the bullfight and the editing process both occur on a probability scale.

A scene from Intacto (Juan Carlos Fresnadillo, 2001) illustrates this dynamic perfectly. In voice-over accompanying a slow-motion sequence of a bull winning from the bullfighter, a retired torero, Alejandro, expresses the thrill of the profession and then explains why he quit:

A great fight can only come out of fear. Not fear of failure, not with a real bullfighter. But fear of pain... yours, those around you, your gang. That fear that makes you look for what's real through bullfighting. [...] And I lost my fear of the bull, without that you can't fight.

A real bullfighter won't lose the game - at least not his life, if he is skilful and all goes according to the rules - but for a worthy fight, fear must be present: it simply would not work otherwise. Alejandro then found another place to look for what's real': gambling on life and death with a select group of four, all extremely gifted: lucky people. One of them is Tomas, a novice in the game and the main protagonist of the film. As the sole survivor of a plane crash, he catches the attention of the gambling organization:

- You're a lucky man, Tomas... the chances of a plane crash are 1/1.000.000. The chances of a crash with you as the sole survivor - out of how many? 237 passengers? - are 237.000.000/1. Why were you the only survivor of that crash? Why? There were many good people on board. What saved you, a common thief: God?

- Chance.

- For you, there's no such thing. Your gift lets you take other people's luck. All you need is luck.

The story unfolds as a knockout, including running through a forest and crossing busy highways blindfolded, guessing games and fraudulent practices 
with a life-insurance company. Out of the four players only one will survive to play the end game, which is a Russian roulette with Samuel (performance by Max von Sydow), mastermind of the game. His luck was proven at a young age, when he was the only child in his pavilion to survive the Holocaust. Before Tomas gets to play the final game (and wins), Samuel tells him his childhood story:

I don't usually talk to the people I'm going to play. But this time I will make an exception. Every morning, the door of the barrack would open, and they took a few out. First the oldest, then our parents, then their brothers and sisters. In a couple of weeks, there were only about fifty of us left, all children. Suddenly, they just stopped coming. Then one day a man appeared, he was not a guard, he was wearing a sand-coloured suit. Spotless, it was. And he held a black handkerchief to his nose (we didn't smell too good, you see), and one by one he took us by the arm and jotted our numbers down in his notebook. We would be 'called and reunited with our parents', and then he left and never came back. But the guards returned, they lined us up and shouted a number - and I looked at my arm, it wasn't me, it was one of the others. And as he walked to the door he turned and looked at us all, thrilled to bits that he won, and disappeared. And so on, every day another number... or two, or none. [...] In the end, only Daniel and I were left, for four days alone. [...] Daniel knew that it wasn't our parents waiting for us on the other side. And the day the door opened again, I took my friend's hand and closed my eyes, willing it not to be my number. When Daniel let go, I couldn't open my eyes, I didn't want to look at his face. The next time the doors opened, the uniforms had changed.

Ultimately, the film conflates gambling and betting with larger-than-life tragedies like the Holocaust, thus making explicit an implied philosophy of existence. Does luck play a role in real-life events? (Could Samuel have been the next to last child?) Are some privileged in this regard, or is everything left to chance? (Why was Tomas, a petty thief, the sole survivor?) In the concluding section, I will argue that the idea of a wager bears explicitly existentialist questions and as such also pervades Bazin's realist paradigm.

\subsubsection{Les jeux sont faits: rien ne va plus?}

Samuel offers three options for Tomas' survival of the plane crash: God, chance, or luck. However, all these options give the characters little agency. 
Surviving a blindfolded run through a forest, for example, has little to do with skill or tactics. Similarly, no single strategy is proven to be effective in winning at American, French, or even Russian roulette: as much as they rely on chance events (themselves unpredictable), once the dice are thrown nothing can change the outcome. As the traditional phrase puts it, les jeux sont faits, rien ne va plus! From this perspective, then, gambling in and of itself effaces the authenticity of the outcome: the ball could have fallen on any number, the winner in fact is as gifted as all the losers together. Without agency, these narratives do not 'make [the characters] aware of [their] freedom and possibilities', ${ }^{93}$ as existentialists would have it. Thus, the existentialist's maxim 'existence precedes essence' questions a predetermined outcome based on chance, and instead affirms the necessity of agency and participation in fate. In Ingmar Bergman's The Seventh Seal (1957) - an obligatory title in this discussion - a knight, Antonius Blok (again, performance by Max von Sydow), encounters the Grim Reaper on his way back from a crusade (the film is set in the Middle Ages against the backdrop of the Black Plague). The Grim Reaper has been following him for quite some time now and decides to introduce himself. Rather than accepting his fate, Antonius negotiates extra time, which he will use 'for one meaningful deed', since his life so far has been 'a futile pursuit'. He seals a deal:

You play chess, don't you? [...] I've seen it in paintings and heard it in songs. [...] The condition is that you let me live for as long as I can stand against you. If I win, you let me go.

The game of chess frames the film and regularly appears as a prop on set whilst Antonius embarks on a quest for 'knowledge, not faith, not suppositions, but knowledge'. The fact that Death plays chess is important from an existentialist point of view: if the all-famous phrase 'God does not throw dice' may counter an aleatory approach to events in life, a chess-playing Grim Reaper suggests that there are rules and tactics involved, at least to some extent. Death will always win, of course, but when that time comes and Antonius is checkmated, Death asks him: 'What have you gained by this reprieve?', to which Antonius answers: 'a great deal!' Instead of being one moment after the other, or rather: one probability like any other, death for Antonius appears to be qualified. 
Both Tomas in Intacto and Antonius in The Seventh Seal look for an essential principle in life (luck, chance, maybe God for Tomas or knowledge for Antonius), and in doing so they test the limits of a certain death. In short, in order to find 'what's real' (the most authentic), they must challenge a determined course of events (the most probable) by means of a wager. The notion of a wager, in particular a calculated and reasoned wager, in relation to existentialist thought goes a long way. In his Pensées, the French philosopher, physician, inventor and mathematician Blaise Pascal (1623-1662) draws out his renowned wager over the existence of God, which would in combination with his mathematical work be seen to touch upon the foundations of calculus and prefigure mathematical probability theory. Pascal first stresses the necessity of the wager, and then considers reason alone as unfit to solve the dilemma of the existence of God:

'God is, or He is not.' But to which side shall we incline? Reason can decide nothing here. There is an infinite chaos which separated us. A game is being played at the extremity of this infinite distance where heads or tails will turn up. What will you wager? According to reason, you can do neither the one thing nor the other; according to reason, you can defend neither of the propositions. [...] but you must wager. It is not optional. You are embarked.

You have two things to lose, the true and the good; and two things to stake, your reason and your will, your knowledge and your happiness; and your nature has two things to shun, error and misery. Your reason is no more shocked in choosing one rather than the other, since you must of necessity choose. This is one point settled. But your happiness? Let us weigh the gain and the loss in wagering that God is. Let us estimate these two chances. If you gain, you gain all; if you lose, you lose nothing. Wager, then, without hesitation that He is. [...] [T]here is here an infinity of an infinitely happy life to gain, a chance of gain against a finite number of chances of loss, and what you stake is finite. It is all divided; wherever the infinite is and there is not an infinity of chances of loss against that of gain, there is no time to hesitate, you must give all. And thus, when one is forced to play, he must renounce reason to preserve his life, rather than risk it for infinite gain, as likely to happen as the loss of nothingness. ${ }^{94}$

Possibly the most well-known and pronounced account of Pascal's wager on screen is Eric Rohmer's My Night at Maud's (1969), which draws clear 
parallels between Pascal's wager and its mathematical implications as related to probability theory. Jean-Louis (Jean-Louis Trintignant), an engineer and practicing Catholic with a passion for maths and probability theory, walks into a bookshop and, after skimming through a new publication on probability, stumbles upon the Pensées. Later on, he reconnects with his old college friend Vidal, an atheist Marxist and philosophy professor at the local university, and their conversation sets the ground for the further development of the narrative:

- Jean-Louis: Are you interested in mathematics?

- Vidal: It's increasingly important for a philosopher. In linguistics, for example. But even basic things. Pascal's arithmetical triangle is connected to his wager. That's what makes Pascal so amazingly modern. Mathematician and philosopher are one.

- J.-L.: Good old Pascal.

- V.: Are you surprised?

- J.-L.: Funny you mention him, I'm just rereading him at the moment. [...] I'm very disappointed. [...] I feel I know him almost by heart, and yet he tells me nothing. I find it all so empty. I'm a Catholic, or at least I try to be, but he doesn't fit in my notion of Catholicism. It's exactly because I'm a Christian that his austerity offends me. If that's what Christianity is about, then I'm atheist. Are you still Marxist?

- V:: Absolutely. For a communist, Pascal's wager is very relevant today. Personally, I very much doubt that history has any meaning. Yet I wager that it has, so I'm in a Pascalian situation. Hypothesis A: Society and politics are meaningless. Hypothesis B: History has meaning. I'm not at all sure B is more likely to be true than A. More likely the reverse. Let's even suppose $B$ has a 10 percent chance of being true, and $A$ has 8 o percent. Nevertheless... I have no choice but to opt for B, because only the hypothesis that history has meaning allows me to go on living. Suppose I bet on A, and B was true, despite the lesser odds. I'd have thrown away my life. So, I must choose B to justify my life and actions. There's an 80 percent chance I'm wrong, but that doesn't matter.

- J.-L.: Mathematical hope. Potential gain divided by probability. With your hypothesis B, though the probability is slight, the possible gain is infinite. in your case, a meaning to life. In Pascal's, eternal salvation.

- V.: It was Gorky, Lenin or maybe Mayakovsky who said about the Russian revolution that the situation forced them to choose the one chance in a thousand. Because hope became infinitely greater if you took that chance than if you didn't take it. 
Vidal, a reasonable man, translates Pascal's God into meaningfulness as opposed to nothingness: he opts for B to 'justify his life and actions', regardless of the possibility that he chooses wrongly. As such, Pascal's wager implies a particular inadequacy of rational arguments. Terrence Penelhum writes about this that:

The most oft-quoted passage of Pascal is the one that says the heart has its reasons which the reason does not know. This is not, I would suggest, a simple appeal to wallow in emotionalism, but partly a way of saying that the canons of rationality of belief and unbelief are different. If the Wager argument is right, the bridge between the two can be crossed by a process which will be differently described by both sides, but which will have its rational element whichever way it is viewed. ${ }^{95}$

Just as Pascal emphasizes the necessity of wagering the existence of God, Bazin rules out the possibility of escaping the bet: in the presence of the camera, a choice - Daney calls it a qualitative leap - has to be made. Similarly, the 'I know, but all the same' paradigm put forth by Daney suggests that reason is not the deciding factor in these types of bets. This paradigm of infinite gain over finite loss, then, accurately reflects what proves to be a pragmatic paradigm of choice guiding the insoluble dilemma between image and reality: we have no choice but to choose. Choice is, in this manner, an existential agency that defies a predetermined course of events (like death).

In this chapter, I presented Bazin's original take on integral realism as a rejection of medium essentialism (in particular Claude Mauriac but also Jean Epstein and even Roger Leenhardt). From a similar perspective, Angela Dalle Vacche suggests that Bazin instead was more affiliated with Gabriel Marcel's notion of 'ontological exigency' rather than engaging in the intended essentialist mind-set of Mauriac's 'cinematic specificity'. She argues that '[i]t is in the margins of the unknown that photography and the cinema explore and expose in ways no other medium, craft, digital imaging, or art form can even begin to match. ${ }^{96}$ Whereas my analyses have shown that Bazin's realism, when it is understood as a wager, in fact equally applies to digital image techniques, there is indeed a strong connection with Marcel's

95 Penelhum, 1964, pp. 206-207.

96 Dalle Vacche, 2011, p. 150. For a detailed analysis of Bazin's affinity with Marcel on the cross-influence between cinema and other arts, see 3.1 Debates on Contemporary Art: Bazin, Marcel and Portmann. 
philosophy of existence, in which ontological exigency plays a crucial role. He explains this process as follows:

Being is - or should be - necessary. It is impossible that everything should be reduced to a play of successive appearances which are inconsistent with each other... or, in the words of Shakespeare, to 'a tale told by an idiot'. I aspire to participate in this being, in this reality - and perhaps this aspiration is already a degree of participation, however rudimentary. ${ }^{97}$

Here, Marcel's ontological exigency indeed resonates with the realist wager discussed in this chapter, as well as with Bazin's rejection of medium essentialism. Marcel acknowledges that it is participation in reality, which is like choice necessary: an exigency that defines being or essence. Rather than a tale told by an idiot, life is meaningful and participation can change the course of history. In the following chapter, I will solidify the connection between Bazin and Marcel in their shared views on the social function of art, cinema in particular, in post-war society. This will bring me to the consequence of Bazin's anti-essentialist stance, as it involves his rigorous work on the undeniable relation between the medium of film and other art forms, of which I will single out his discussions on cinema in relation to painting and poetry

\section{Bibliography}

Albera, François (2016). “The Heritage We Renounce:” Eisenstein in Historiography.' In: Sergei M. Eisenstein: Notes for a General History of Cinema. Eds. Kleiman, Naum \& Antonio Somaini. Amsterdam: Amsterdam University Press.

Andrew, Dudley (1976). The Major Film Theories: An Introduction. New York: Oxford University Press.

--- (2007). 'A Film Aesthetic to Discover.' Cinémas:Journal of Film Studies, Vol. 17, No. 2-3: pp. 47-71.

--- (2012). 'Malraux, Benjamin, Bazin.' In: Film, Art, New Media: Museum without Walls? Ed. Angela Dalle Vacche. New York: Palgrave Macmillan, pp. 115-140.

--- (2013). André Bazin. New York: Oxford University Press.

Aumont, Jacques (1989). L'CEil interminable: Cinéma et peinture. Paris: Librairie Siguier.

Bazin, André (1945). 'Ontologie de l'image photographique.' Qu'est-ce que le cinéma? Paris: Éditions du Cerf (2008): pp. 9-18. EC OP, 1.

--- (1948c). 'Le Réalisme cinématographique et l'école italienne de la Libération.' Esprit, No. 141 (January). EC V, 362.

--- (1948d). 'William Wyler ou le janséniste de la mise en scène.' Qu'est-ce que le cinema? Vol. 1: Ontologie et langage. Paris: Éditions du Cerf (1958). EC V, 382. 
--- (1949c). 'Mort tous les après-midi.' Qu'est-ce que le cinema? Tome 1: Ontologie et langage. Paris: Éditions du Cerf (1958): pp. 65-7o. EC IX, 899.

--- (1951a). 'Le Journal d'un cure de campagne et la stylistique de Robert Bresson.' Qu'est-ce que le cinema? Paris: Éditions du Cerf (2008): pp. 107-128. EC IX, 798.

--- (1952a). 'Une grande œuvre: Umberto D.' Qu'est-ce que le cinéma? Paris: Éditions du Cerf (2008): pp. 131-337. EC XI, 1141.

--- (1953-1954). 'Le Cinéma et l'exploration.' Qu'est-ce que le cinéma? Paris: Éditions du Cerf (2008): pp. 25-34. EC OP I, 7.

--- (1953-1957). 'Montage interdit.' Qu'est-ce que le cinéma? Paris: Éditions du Cerf (2008): pp. 50-61. EC OP I, 16.

---(1955a). 'L'Évolution du film d'exploration.' Le Monde nouveau (May). EC XVII, 1754. EC OP, 17.

--- (1956b). 'Le Monde du silence: Icare sous-marin.' Radio cinéma télévision, No. 319 (26 February). EC XIX, 1993.

--- (1958a). 'Avant-propos.' Qu'est-ce que le cinéma? Tome 1: Ontologie et langage. Paris: Éditions du Cerf (1959): pp. 7-9. EC OP I.

Chevrier, Jean-François (2011). 'The Reality of Hallucination in André Bazin.' In: Opening Bazin: Postwar Film Theory and Its Aftermath. Eds. Dudley Andrew and Hervé Joubert-Laurencin. New York: Oxford University Press, pp. 42-55.

Dall'Asta, Monica (2011). 'Beyond the Image in Benjamin and Bazin: The Aura of the Event.' In: Opening Bazin: Postwar Film Theory and Its Aftermath. Eds. Dudley Andrew and Hervé Joubert-Laurencin. New York: Oxford University Press, pp. 57-65.

Dalle Vacche, Angela (2011). 'The Difference of Cinema in the System of the Arts.' In: Opening Bazin: Postwar Film Theory and Its Aftermath. Eds. Dudley Andrew and Hervé Joubert-Laurencin. New York: Oxford University Press, pp. 142-152.

--- (2016). 'Miraculous Mathematics: André Bazin's Film Theory.' Discourse, Vol.38, No.2 (Spring): pp. 117-141.

Daney, Serge (1972). 'The Screen of Fantasy (Bazin and Animals).' Transl. Mark A. Cohen. In: Rites of Realism: Essays on Corporeal Cinema. Ed. Ivone Margulies. Durham: Duke University Press (2002): pp. 32-41.

Doane, Mary Ann (2003). The Emergence of Cinematic Time: Modernity, Contingency, the Archive. Cambridge: Harvard University Press.

Epstein, Jean (1921). ‘Bonjour cinéma.' In: Écrits sur le cinéma 1921-1953. Vol ı. Ed. Pierre Lherminier. Paris: Éditions Saghers (1974): pp. 71-104.

--- (1926). 'Le Cinématographe vu de l'Etna.' In: Écrits sur le cinéma 1921-1953. Vol 1. Ed. Pierre Lherminier. Paris: Éditions Saghers (1974): pp. 131-168.

--- (1946). 'Intelligence d'une machine.' In: Écrits sur le cinéma 1921-1953. Vol 1. Ed. Pierre Lherminier. Paris: Éditions Saghers (1974): pp. 255-354.

---(1947). 'La Logique des images.' In: Écrits sur le cinéma 1921-1953. Vol 2. Ed. Pierre Lherminier. Paris: Éditions Saghers (1975): pp. 30-33.

Gheeraert, Tony. 'Pascal et les reines de village: baroque et maniérisme à Port-Royal.' Études epistèmè, No. 9 (2006): pp. 285-305.

Hemingway, Ernest (1932). Death in the Afternoon. London: Vintage Books, 2000.

Joubert-Laurencin, Hervé. Le Sommeil paradoxal: écrits sur André Bazin. Montreuil: Les Éditions de l'CEil (2014).

Marcel, Gabriel (1933). 'On the Ontological Mystery.' In: The Philosophy of Existentialism. Transl. Manya Harari. New York: The Citadel Press (1970): pp. 9-46.

Michalson, G.E. (1979). 'Lessing, Kierkegaard, and the "Ugly Ditch": A Reexamination.' The Journal of Religion, Vol. 59, No. 3 (July): pp. 324-334. 
Newton, Isaac (1684). The Principia: Mathematical Principles of Natural Philosophy. Transl. Bernard

Cohen, Anne Whitman and Julia Budenz. Berkeley: University of California Press, 1999.

Pascal, Blaise (1670). Pascal's Pensées. Transl. W.F. Trotter. New York: E.P. Dutton \& Co., $195^{8}$.

Penelhum, Terence. 'Pascal's Wager.' Journal of Religion, Vol. 44, No. 3 (1964): pp. 201-209.

Peres, Asher (1995). Quantum Theory: Concepts and Methods. Dordrecht: Kluwer Academic Publishers.

Schrödinger, Erwin (1935). 'The Present Situation in Quantum Mechanics: A Translation of Schrödinger's “Cat Paradox Paper." Transl. John D. Trimmer. In: Quantum Theory and Measurement. Eds. J.A. Wheeler and W.H. Zurek. New Jersey: Princeton University Press (1983): pp. 152-167.

Stapp, Henry Pierce (1972). 'The Copenhagen Interpretation.' American Journal of Physics, Vol. 40, No. 1098: pp. 1098-1116.

Tweedie, James (2011). 'André Bazin's Bad Taste.' In: Opening Bazin: Postwar Film Theory and Its Aftermath. Eds. Dudley Andrew and Hervé Joubert-Laurencin. New York: Oxford University Press: pp. 275-287.

\section{Other sources}

'Kon-Tiki: The Incredible True Story: Shooting in Open Water.' National Geographic. [Accessed 28/05/2014] <http://channel.nationalgeographic.com/channel/videos/ shooting-in-open-water/>.

'Death Jump - Eiffel Tower 1912.' British Pathé. [Accessed 28/05/2014] <http://www.britishpathe. com/video/death-jump-eiffel-tower/query/reichelt>.

'Jaws: Trivia.' The Internet Movie Database. [Accessed 28/05/2014] < http://www.imdb.com/title/ ttoo73195/trivia?ref_=tt_trv_trv>.

'Kon-Tiki: Complete VFX-Breakdown.' YouTube. [Accessed 28/05/2014] <http://www.youtube. com/watch?v=gFpL2XzAn44>.

'Shark! Trivia.' The Internet Movie Database. [Accessed 26/04/2019] <https://www.imdb.com/ title/ttoo66365/trivia?ref_=tt_trv_trv>.

Trier, Joachim \& Harvey Weinstein. “Kon-Tiki” Directors Discuss the Making of Their Offshore Epic (Q\&A).' The Hollywood Reporter (26/04/2014) [Accessed 28/05/2014] <http://www.hollywoodreporter.com/news/kon-tiki-directors-discuss-making-447386>.

\section{Used translations}

Daney, Serge (1972). 'The Screen of Fantasy (Bazin and Animals).' Transl. Mark A. Cohen. In: Rites of Realism: Essays on Corporeal Cinema. Ed. Ivone Margulies. Durham: Duke University Press (2002): pp. 32-41.

Bazin, André. What Is Cinema? Vol. 1 \& 2. Transl. Hugh Gray. Berkeley: University of California Press (2005).

---. What Is Cinema? Transl. Timothy Barnard. Montreal: Caboose (2009). 
Epstein, Jean. 'The Cinema Seen from Etna.' Transl. Stuart Liebmann. In:Jean Epstein: Critical essays and New Translations. Eds. Sarah Keller and Jason N. Paul. Amsterdam: Amsterdam University Press (2012): pp. 287-310.

---. 'The Logic of Images.' Transl. Thao Nguyen. In:Jean Epstein: Critical essays and New Translations. Eds. Sarah Keller and Jason N. Paul. Amsterdam: Amsterdam University Press, (2012): pp. 330-333.

\section{Filmography}

Man of Aran (Robert J. Flaherty, 1934)

Diary of a Chambermaid [Journal d'une femme de chambre] (Jean Renoir, 1946)

Paisà (Roberto Rossellini, 1946)

Paris 19oo (Nicole Védrès, 1947)

Kon-Tiki (Thor Heyerdahl, 1950)

Bullfight (Myriam Borsoutsky \& Pierre Braunberger, 1951)

Umberto D. (Vittorio De Sica, 1952)

The Seventh Seal (Ingmar Bergman, 1957)

My Night at Maud's [Ma nuit chez Maud] (Eric Rohmer, 1969)

Jaws (Steven Spielberg, 1975)

Intacto (Juan Carlos Fresnadillo, 2001)

Kon-Tiki (Joachim Rønning \& Espen Sandberg, 2012)

\section{Illustrations}

Figure 2. Diagram of Isaac Newton's Calculus, Principia Lemma II

Figure 3-8. Film stills from Umberto D. (Vittorio De Sica, 1952) 
